\title{
Experimental Study on Wettability of Xinjiang Oilfield Crude Oil on Two Kinds of Non-Metallic Pipes
}

\author{
Yan $\mathrm{Wu}^{1}, \mathrm{Yu} \mathrm{Li}^{2}$, Xinjun $\mathrm{Gu}^{2}$, Ziyan Wen ${ }^{3, a}$, Zhian Deng ${ }^{3}$, Kai Yi ${ }^{3}$ \\ ${ }^{1}$ The Research Institute of Engineering and Technology, Xinjiang Oilfield Company, Xinjiang 834000, China \\ ${ }^{2}$ Development Company, Xinjiang Oilfield Company, Xinjiang 834000, China \\ ${ }^{3}$ College of Petroleum Engineering, Xi'an Shiyou University, Xi'an 710065, China
}

\begin{abstract}
In recent years, non-metallic pipes have been widely used in oilfield development due to their excellent corrosion resistance. In this paper, the wettability of flexible composite pipe and plastic alloy pipe surface was studied for some crude oil in Xinjiang oilfield. The wettability of the surface of the flexible composite pipe and the surface of the plastic alloy pipe and its influence on the flow resistance were discussed, and the wettability of the crude oil on the metal surface was compared. This experimental study has certain guiding significance for the judgment of pressure drop of crude oil conveyed by flexible composite pipe and plastic alloy pipe.
\end{abstract}

\section{Introduction}

Corrosion of metal pipelines has always affected the stable and safe operation of oil gas field surface engineering, and is one of the important reasons that restrict the rapid development of the petroleum industry. Due to its excellent corrosion resistance and hydraulic properties, non-metallic pipes have the advantages of smooth inner wall, low friction, low energy consumption, no need for cathodic protection, long service life and good economic benefits. Non-metallic pipes have been widely concerned and applied by the petrochemical industry at home and abroad. At present, the non-metallic pipelines used in oil fields mainly include high pressure fiberglass pipes, steel skeleton polyethylene plastic composite pipes, continuous reinforced plastic composite pipes and plastic alloy composite pipes. The Daqing Oilfield No.2 Oil Production Plants carried out the application test of high-pressure FRP pipelines in the South 7-40-621 well and the South 7-40624 well in 1994. After successful test, the high-pressure glass steel pipe was applied to the water injection pipeline and single well oil gathering ${ }^{[1]}$. Jilin Oilfield applied 9.2 $\mathrm{km}$ of epoxy FRP pipes on the external oil pipeline between Yingtai and Honggang (working pressure 4.0 $\mathrm{MPa}$ ) to solve the pipeline corrosion problem ${ }^{[2]}$. Xinjiang Karamay Oilfield uses steel skeleton polyethylene plastic composite pipe as the oil gathering dry branch line and single well oil gathering pipeline to transport oil well production fluid, which solves the pipeline corrosion problem of conveying water crude oil ${ }^{[3]}$. Liao He Oilfield applied plastic alloy composite pipe from 2002. The transportation medium is mainly sewage and crude oil, and the maximum service temperature reaches $70{ }^{\circ} \mathrm{C}{ }^{[4]}$. Although non-metallic pipelines play a major role in oilfield water injection and gathering and transportation production, in the process of use, there is no combination of oilfield transport medium characteristics, and reasonable selection of non-metallic pipeline types.

Therefore, the performance of different types of nonmetallic pipes cannot be fully utilized to meet the oilfield production requirements, resulting in poor applicability of some non-metallic pipes. Reservoir adhesion, wax deposition and scaling occur on the inner wall of the pipeline, resulting in increased back pressure of oil gathering and single well pipelines, reduced crude oil production, insufficient injection of injection wells, and increased maintenance costs. Through these phenomena, it can be found that the low friction characteristics of nonmetallic pipes are not fully exerted. Therefore, it is necessary to study the wettability of medium and nonmetallic pipes, reasonably select pipes, improve the reliability and availability of pipes, and ensure the normal production of oil fields.

\section{Experimental samples and conditions}

\subsection{Experimental sample}

The experimental samples are crude oil and tap water in the Luliang oil area and the Hongqian oil area of Xinjiang Oilfield. The crude oil properties are shown in Table 1 and Table 2.

Table 1. Crude oil properties in the Luliang oil area

\begin{tabular}{|c|c|c|c|}
\hline $\begin{array}{c}\text { Oil density } \\
(\mathrm{kg} / \mathrm{m} 3)\end{array}$ & $\begin{array}{c}\text { Viscosity } \\
(\mathrm{mPa} \bullet \mathrm{s})\end{array}$ & $\begin{array}{c}\text { Freezing } \\
\text { point }\end{array}$ & $\begin{array}{c}\text { Reverse } \\
\text { phase } \\
\text { point }\end{array}$ \\
\hline
\end{tabular}

\footnotetext{
${ }^{a}$ Corresponding author: 1249988724@qq.com
} 


\begin{tabular}{|c|c|c|c|c|c|}
\hline $20^{\circ} \mathrm{C}$ & 889.3 & $20^{\circ} \mathrm{C}$ & 10600 & \multirow{2}{*}{$20.5^{\circ} \mathrm{C}$} & \multirow{3}{*}{$35 \sim 45 \%$} \\
\hline $40^{\circ} \mathrm{C}$ & 867.2 & $40^{\circ} \mathrm{C}$ & 433 & \\
\hline $60^{\circ} \mathrm{C}$ & 854.5 & $60^{\circ} \mathrm{C}$ & 52 & & \\
\hline
\end{tabular}

Table 2. Crude oil properties in the Hongqian oil area

\begin{tabular}{|c|c|c|c|c|c|}
\hline \multicolumn{2}{|c|}{$\begin{array}{c}\text { Oil density } \\
(\mathrm{kg} / \mathrm{m} 3)\end{array}$} & \multicolumn{2}{|c|}{$\begin{array}{c}\text { Viscosity } \\
(\mathrm{mPa} \bullet \mathrm{s})\end{array}$} & \multirow{2}{*}{$\begin{array}{c}\text { Freezing } \\
\text { point }\end{array}$} & $\begin{array}{c}\text { Reverse } \\
\text { phase } \\
\text { point }\end{array}$ \\
\hline $20^{\circ} \mathrm{C}$ & 821.3 & $20^{\circ} \mathrm{C}$ & 53.2 & \multirow{2}{*}{$16.5^{\circ} \mathrm{C}$} & \multirow{2}{*}{$10 \sim 20 \%$} \\
\hline $40^{\circ} \mathrm{C}$ & 813.2 & $40^{\circ} \mathrm{C}$ & 5.9 & \\
\hline $60^{\circ} \mathrm{C}$ & 800.9 & $60^{\circ} \mathrm{C}$ & 3.9 & & \\
\hline
\end{tabular}

\subsection{Experimental temperature and pressure}

Normal temperature and pressure.

\subsection{Experimental instrument}

Interfacial tension measuring instrument, model JC2000C1.

\section{Experimental results and discussion}

\subsection{Surface tension}

The surface tension of tap water, Luliang crude oil and Hongqian crude oil were measured as shown in Fig. 1 to Fig. 3, and the surface tension data is shown in Table 3.

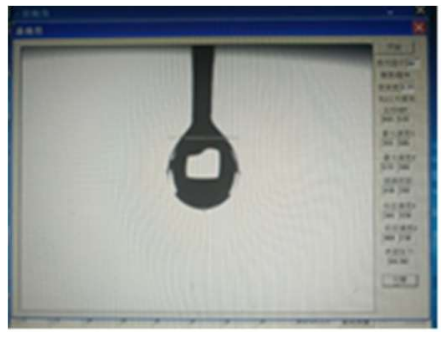

Figure 1. water surface tension

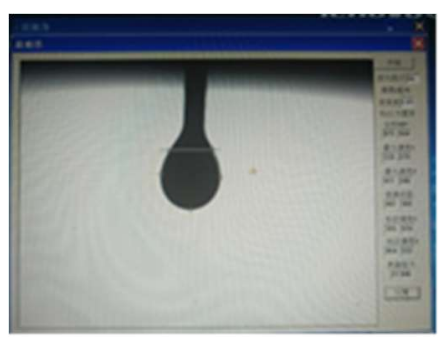

Figure 2. Surface tension of Luliang crude oil

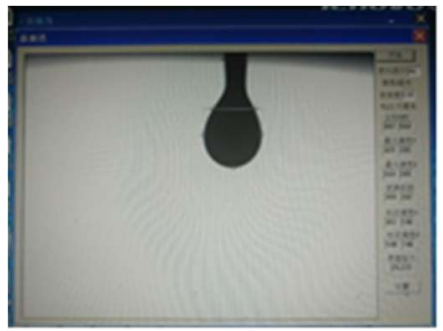

Figure 3. Surface tension of Hongqian crude oil

\footnotetext{
${ }^{a}$ Corresponding author: 1249988724@qq.com
}

Table 3. Experimental media surface tension data

\begin{tabular}{|c|c|c|}
\hline Water $(\mathrm{N} / \mathrm{m})$ & Luliang oil $(\mathrm{N} / \mathrm{m})$ & Hongqian oil $(\mathrm{N} / \mathrm{m})$ \\
\hline $64.38 \times 10^{-3}$ & $27.85 \times 10^{-3}$ & $25.28 \times 10^{-3}$ \\
\hline
\end{tabular}

From the surface tension test, it is found that the surface tension of Luliang crude oil and Hongqian crude oil is much smaller than that of water, and the surface tension of crude oil in the two oil areas is not much different.

\subsection{Wettability test on different pipe surfaces}

In this experiment, static wettability experiments were carried out on the inner surface of flexible composite pipe, plastic alloy pipe and the surface of $20 \#$ steel plate with water, land-beam crude oil and red-shallow crude oil as medium. Testing the contact angle of different media on the surface of two non-metallic tubes and steel plate. Figure 4-6 shows the experimental angle of the contact angle of three media on the surface of three materials.

From left to right, flexible composite pipe, plastic alloy pipe and $20 \#$ steel plate.
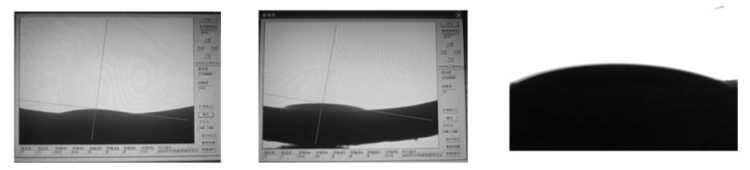

Figure 4. Contact angle of Luliang crude oil on the surface of three materials

From left to right, flexible composite pipe, plastic alloy pipe and $20 \#$ steel plate.
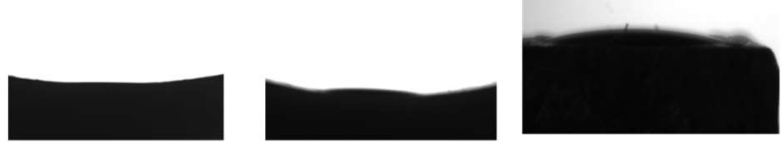

Figure 5. Contact angle of Hongqian crude oil on the surface of three materials

From left to right, flexible composite pipe, plastic alloy pipe and 20\# steel plate.
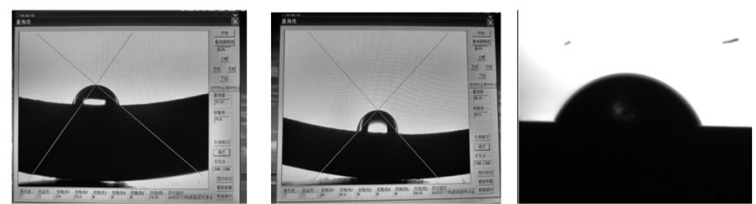

Figure 6. Contact angle of water on the surface of three materials

Table 4. Experimental data of contact angle

\begin{tabular}{|c|c|c|c|}
\hline \multirow{2}{*}{ Type } & \multicolumn{3}{|c|}{$\begin{array}{c}\text { Contact angle } \theta \text { (Angle } \\
\text { measuring method) } /{ }^{\circ}\end{array}$} \\
\cline { 2 - 4 } & Left & Right & Average \\
\hline $\begin{array}{c}\text { Luliang crude oil and flexible } \\
\text { composite pipe }\end{array}$ & 12.5 & 14.5 & 13.50 \\
\hline $\begin{array}{c}\text { Luliang crude oil and plastic } \\
\text { alloy pipe }\end{array}$ & 12.5 & 19 & 15.75 \\
\hline $\begin{array}{c}\text { Luliang crude oil and 20\# steel } \\
\text { plate }\end{array}$ & 18.33 & 18.33 & 18.33 \\
\hline $\begin{array}{c}\text { Hongqian crude oil and flexible } \\
\text { composite pipe }\end{array}$ & - & - & $<10.00$ \\
\hline \multicolumn{2}{|c|}{} \\
\hline \multicolumn{2}{|c|}{}
\end{tabular}




\begin{tabular}{|c|c|c|c|}
\hline $\begin{array}{c}\text { Hongqian crude oil and plastic } \\
\text { alloy pipe }\end{array}$ & - & - & $<10.00$ \\
\hline $\begin{array}{c}\text { Hongqian crude oil and 20\# } \\
\text { steel plate }\end{array}$ & 63.6 & 63.6 & 63.6 \\
\hline $\begin{array}{c}\text { Water and flexible } \\
\text { composite pipe }\end{array}$ & 74 & 75.5 & 74.75 \\
\hline $\begin{array}{c}\text { Water and plastic alloy } \\
\text { pipe }\end{array}$ & 97 & 91.5 & 94.25 \\
\hline $\begin{array}{c}\text { Water and 20\# Steel } \\
\text { Plate }\end{array}$ & 62.88 & 62.88 & 62.88 \\
\hline
\end{tabular}

It can be seen from Fig. 4-6 and Table 4 that the contact angle of the Luliang crude oil on the surface of the $20 \#$ steel plate is small. From the slight difference, the wetting angle of the Luliang crude oil on the surface of the $20 \#$ steel plate is larger than that of the plastic alloy. indicating that under the same conditions of the pipe flow conditions, the flow resistance of water will be slightly lower.

The contact angle of the Hongqian crude oil on the surface of the flexible composite pipe and the plastic alloy pipe is very small, less than $10^{\circ}$, and the contact angle on the surface of the $20 \#$ steel plate is large, indicating that the flow resistance of Hongqian crude oil in flexible composite pipes and plastic alloy pipes is much greater than that in metal pipes under the same conditions of the pipe flow conditions.

The contact angle of water on the surface of the flexible composite pipe and the plastic alloy pipe is the largest, and the wetting angle on the surface of the plastic alloy pipe exceeds $90^{\circ}$, indicating that the material has hydrophobic characteristics.

From the wetting behavior of the three media on the surface of the three materials, the wettability of water is the worst, while the Hongqian crude oil has the best wettability on the surface of flexible composite pipe and plastic alloy pipe, followed by Luliang crude oil. It can be concluded that the wettability of the red-light crude oil and the Luliang crude oil on the surface of the two non-metallic pipelines is better than that of the water. That is to say, under the same conditions of the intra-tube flow conditions, the contact area of crude oil on the surface of the two nonmetallic pipes is much larger than that of water. For in-pipe flow, it means that the flow resistance of red light crude oil and land beam crude oil in these two non-metallic pipes has a tendency to be greater than the water flow resistance, which also shows that the flow friction coefficient of Hongqian crude oil and Luliang crude oil in these two nonmetallic pipes is greater than that of water. At the same time, it is also predicted that the flow resistance of the oil in water emulsion is lower than that of the water in oil emulsion for different emulsion types under the same conditions of intra-tube flow conditions.

It can also be seen from Fig. 4-6 and Table 4 that the wetting property of crude oil on the surface of plastic alloy tube and flexible composite tube is better than that of metal surface, which is different from the wetting behavior of water on metal surface. It also shows that the flow resistance of crude oil on the surface of plastic alloy tube and flexible composite tube is greater than that of metal surface under the same condition of intra-tube flow conditions. In addition, comparing the contact angles of the above three media on the surface of the flexible composite pipe and the plastic alloy pipe, it can also be seen that the contact angles of the three media on the inner surface of the plastic alloy pipe are larger than the contact angle of the inner surface of the flexible composite pipe. That is to say, under the operating conditions, the flow friction of the three media on the inner surface of the plastic alloy pipe is smaller than the flow friction on the inner surface of the flexible composite pipe.

\section{Conclusion}

Through the experiment on the wettability of water, Hongqian crude oil and Luliang crude oil on flexible composite pipe, plastic alloy pipe inner surface and metal surface, it is found that:

(1) The contact angles of the two non-metallic pipes and oils are very small, indicating that the inner walls of the two non-metallic pipes are oleophilic and have a large friction when conveying oil.

(2) Since the wettability of the inner surface of the pipe has a certain influence on the flow resistance, the larger the contact angle, the smaller the friction coefficient. The order of friction of flexible composite pipe and plastic alloy pipe conveying water or two kinds of crude oil is as follows: Hongqian crude oil $>$ Luliang crude oil $>$ water

(3) Under the same conditions of intra-tube flow conditions, the flow resistance of crude oil on the surface of plastic alloy tubes and flexible composite tubes is greater than that of metal surfaces.

(4) From the contact angle data, it can be seen that the plastic alloy pipe has hydrophobic properties, is not easily wetted by water, and has a small frictional resistance when transporting water.

\section{References}

1. Weijun Cai. Non-metallic pipe application and adaptability analysis [J]. Oil-Gasfield Surface Engineering, 2013, 32 (6): 103.

2. Yalin Wang, Yuwu Weng, Jinglong. Application of high pressure fiberglass pipe in Ying-Hong oil pipeline [J]. Oil-Gasfield Surface Engineering, 2000, 19 (1): 22-25.

3. Fengqing He, Yan Wu, Wei Liu, Yuanyuan Hu. Application of non-metallic pipelines in Xinjiang oilfield [J]. Oil-Gasfield Surface Engineering, 2016, 35 (01): 94-96.

4. Zhenzhong Yang, Li Li, Wanru Yang. Analysis of application of non-metallic pipelines in Linpan Oil Production Plant [J]. Inner Mongolia Petrochemical Industry, 2010, 36 (5): 52-53.

\footnotetext{
${ }^{a}$ Corresponding author: 1249988724@qq.com
} 